\title{
Effects of organic selenium in broiler feed on the content of selenium and fatty acid profile in lipids of thigh muscle tissue
}

\author{
Zlata Kralik ${ }^{1}$, Gordana Kralik ${ }^{1}$, Ewa Biazik², Eva Straková3, Pavel Suchý ${ }^{3}$ \\ ${ }^{1}$ Josip Juraj Strossmayer University of Osijek, Faculty of Agriculture, Department of Special Zootechniques, \\ Osijek, Croatia \\ ${ }^{2}$ Wrocław University of Environmental and Life Sciences, Department of Animal Products Technology and \\ Quality Management, Wrocław, Poland \\ ${ }^{3}$ University of Veterinary and Pharmaceutical Science Brno, Faculty of Veterinary Hygiene and Ecology, \\ Department of Nutrition, Animal Husbandry and Animal Hygiene, Brno, Czech Republic
}

Received December 14, 2012

Accepted May 29, 2013

\begin{abstract}
The aim of our study was to determine the effects of selenium supplementation to broiler feed on the content of selenium, total fatty acids in lipids and on the oxidative stability of broiler thigh muscle tissue. The experiment involved 40 broilers fattened for 42 days. During the first three weeks, all broilers consumed starter diet containing $22 \%$ crude protein. After three weeks, broilers were divided into two groups and fed finisher diets containing $18 \%$ crude protein and supplemented with 3\% sunflower oil and 3\% linseed oil. Group 1 was not administered artificial selenium; Group 2 was supplemented with organic selenium at the amount of $0.5 \mathrm{mg} \mathrm{Se} / \mathrm{kg}$ of feed. Significantly higher $(P<0.05)$ content of selenium was observed in the thigh muscle tissue of Group 2 compared to Group 1 ( 1.071 and $0.511 \mathrm{mg} / \mathrm{kg}$ of dry matter, respectively). The increase of selenium content in feed to $0.5 \mathrm{mg} / \mathrm{kg}$ resulted in an increase of total $\mathrm{n} 3$ polyunsaturated fatty acids (from $5.27 \%$ to $6.25 \%$ ), and in reduction of total monounsaturated fatty acids (from $39.60 \%$ to $36.74 \%$ ) in the lipids of thigh muscle tissue. The increase in total $n-3$ polyunsaturated fatty acids induced significant $(P<0.05)$ lowering of the $\mathrm{n} 6 / \mathrm{n} 3$ polyunsaturated fatty acids ratio (4.62 and 5.01 for the first and second group, respectively). The increase of selenium content in broiler feed led to a decrease of thiobarbituric acid reactive substances $(P>0.05)$ and increase of linolenic acid and total n-3 polyunsaturated fatty acids $(P<0.05)$ in thigh muscle tissue of broilers. Since selenium and n-3 polyunsaturated fatty acids are nutricines, our results show that the produced broiler meat may be considered as functional food.
\end{abstract}

Broiler meat, TBARS, MUFA, PUFA

In most European countries, the trend is to increase consumption of poultry meat, which can be explained with the fact that broiler meat is of satisfactory nutritive quality and acceptable to consumers with respect to price and organoleptic traits. Intensive researches are directed towards improvement of the nutritive quality of broiler meat as a functional product. Broiler meat shall be enriched with certain functional ingredients, such as selenium, n-3 polyunsaturated fatty acids (PUFA), etc. The main raw material for broiler feed were cereals, as well as oils as a source of fat for balancing of metabolizable energy (ME). Some authors stated that composition of diets for poultry and supplementation of plant oil (López-Ferrer et al. 1999) or fish oil (López-Ferrer et al. 2001) could affect composition of fatty acids in muscle tissue. Substitution of sunflower oil with fish oil or with linseed oil results in increased portion of total n-3 PUFA, and in decreased portion of total n-6 PUFA. However, food enriched with n-3 PUFA increases sensitivity of cellular membranes to animals' oxidative stress induction (Miret et al. 2003). Moreover, if feed is supplemented with high content of mentioned oils, unpleasant odor and taste of meat and meat products can occur, which causes consumers' rejection of such products (Sparks 2006). Thus it is useful to supplement feed with antioxidants, such as vitamin E, carotenoids or selenium.

Address for correspondence:

Gordana Kralik

K.P. Svačića 1d, 31000 Osijek

Croatia
Phone: 00385(0)31554863

Fax: 00385(0)31207015

E-mail: gkralik@pfos.hr

http://actavet.vfu.cz/ 
The aim of our study was to determine the effects of selenium supplementation to broiler feed on the content of selenium, portions of total fatty acids in lipids and on the oxidative stability of broiler thigh muscle tissue.

\section{Material and Methods}

A total of 40 male Ross 308 hybrid broilers were fattened for the purpose of this experiment. Broilers were fattened for 42 days, upon which they were slaughtered. Broilers were kept in the same conditions, on the ground and on deep litter. Hanging feeders and drinkers were used for feeding and watering. During the first three weeks of fattening, broilers were given starter diet (Table 1) with $22 \%$ crude protein and $13.90 \mathrm{MJ} / \mathrm{kg} \mathrm{ME}$, and during the last three weeks of fattening they were fed finisher diet with $18 \%$ crude protein and $14.67 \mathrm{MJ} / \mathrm{kg} \mathrm{ME}$ (Table 1). Besides other components, finisher diet contained 3\% sunflower oil and 3\% linseed oil. Being three weeks old, broilers were divided into two groups of 20 birds. Group 1 (P1) was fed a diet without supplemented organic selenium (Sel-Plex ${ }^{\circledR}$, Alltech, Czech Republic); however, the diet contained $0.0822 \mathrm{mg}$ selenium $/ \mathrm{kg}$ of feed.

Table 1. Composition of starter and finisher broiler diets

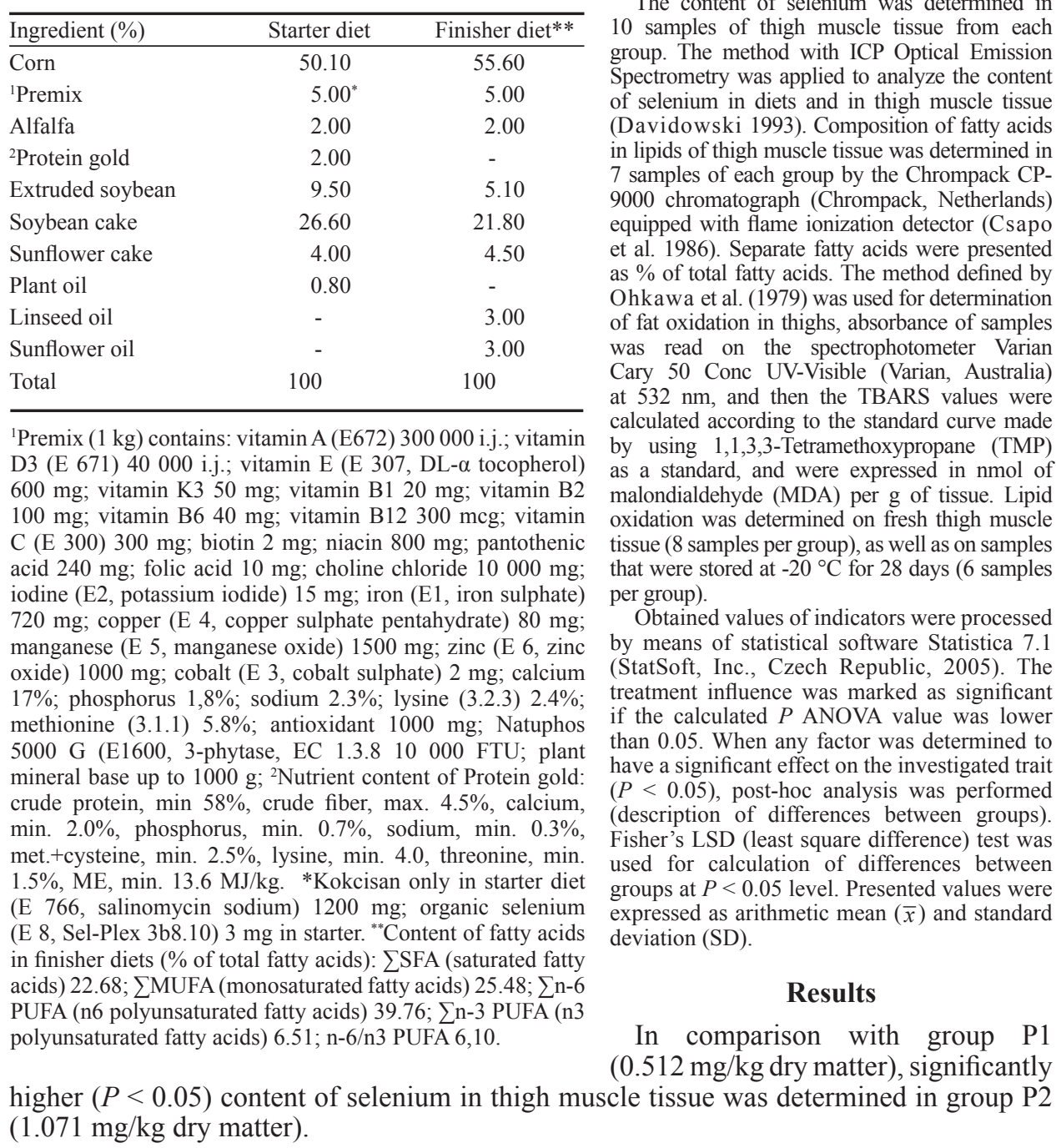

${ }^{1}$ Premix (1 kg) contains: vitamin A (E672) 300000 i.j.; vitamin D3 (E 671) 40000 i.j.; vitamin E (E 307, DL- $\alpha$ tocopherol) $600 \mathrm{mg}$; vitamin $\mathrm{K} 350 \mathrm{mg}$; vitamin B1 $20 \mathrm{mg}$; vitamin B2 $100 \mathrm{mg}$; vitamin B6 40 mg; vitamin B12 300 mcg; vitamin C (E 300) $300 \mathrm{mg}$; biotin $2 \mathrm{mg}$; niacin $800 \mathrm{mg}$; pantothenic acid $240 \mathrm{mg}$; folic acid $10 \mathrm{mg}$; choline chloride $10000 \mathrm{mg}$; iodine (E2, potassium iodide) $15 \mathrm{mg}$; iron (E1, iron sulphate) $720 \mathrm{mg}$; copper (E 4, copper sulphate pentahydrate) $80 \mathrm{mg}$; manganese (E 5, manganese oxide) $1500 \mathrm{mg}$; zinc (E 6, zinc oxide) $1000 \mathrm{mg}$; cobalt (E 3, cobalt sulphate) $2 \mathrm{mg}$; calcium $17 \%$; phosphorus $1,8 \%$; sodium $2.3 \%$; lysine (3.2.3) $2.4 \%$; methionine (3.1.1) 5.8\%; antioxidant $1000 \mathrm{mg}$; Natuphos 5000 G (E1600, 3-phytase, EC 1.3.8 10 000 FTU; plant mineral base up to $1000 \mathrm{~g} ;{ }^{2}$ Nutrient content of Protein gold: crude protein, $\min 58 \%$, crude fiber, max. $4.5 \%$, calcium, min. $2.0 \%$, phosphorus, $\min$. $0.7 \%$, sodium, min. $0.3 \%$, met.+cysteine, $\min$. $2.5 \%$, lysine, $\min$. 4.0, threonine, min. $1.5 \%$, ME, min. $13.6 \mathrm{MJ} / \mathrm{kg}$. *Kokcisan only in starter diet (E 766, salinomycin sodium) $1200 \mathrm{mg}$; organic selenium (E 8, Sel-Plex 3b8.10) $3 \mathrm{mg}$ in starter. ${ }^{* *}$ Content of fatty acids in finisher diets ( $\%$ of total fatty acids): $\sum$ SFA (saturated fatty acids) 22.68; $\sum$ MUFA (monosaturated fatty acids) $25.48 ; \sum n-6$ PUFA (n6 polyunsaturated fatty acids) $39.76 ; \sum n-3$ PUFA (n3 polyunsaturated fatty acids) $6.51 ; n-6 / n 3$ PUFA 6,10 . higher $(P<0.05)$ content of selenium in thigh muscle tissue was determined in group P2 $(1.071 \mathrm{mg} / \mathrm{kg}$ dry matter). supplemented to the diet of Group 2 (P2).

The content of selenium was determined in 10 samples of thigh muscle tissue from each group. The method with ICP Optical Emission Spectrometry was applied to analyze the content of selenium in diets and in thigh muscle tissue (Davidowski 1993). Composition of fatty acids in lipids of thigh muscle tissue was determined in 7 samples of each group by the Chrompack CP9000 chromatograph (Chrompack, Netherlands) equipped with flame ionization detector (Csapo et al. 1986). Separate fatty acids were presented as $\%$ of total fatty acids. The method defined by Ohkawa et al. (1979) was used for determination of fat oxidation in thighs, absorbance of samples was read on the spectrophotometer Varian Cary 50 Conc UV-Visible (Varian, Australia) at $532 \mathrm{~nm}$, and then the TBARS values were calculated according to the standard curve made by using 1,1,3,3-Tetramethoxypropane (TMP) as a standard, and were expressed in nmol of malondialdehyde (MDA) per g of tissue. Lipid oxidation was determined on fresh thigh muscle tissue (8 samples per group), as well as on samples that were stored at $-20^{\circ} \mathrm{C}$ for 28 days (6 samples per group).

Obtained values of indicators were processed by means of statistical software Statistica 7.1 (StatSoft, Inc., Czech Republic, 2005). The treatment influence was marked as significant if the calculated $P$ ANOVA value was lower than 0.05 . When any factor was determined to have a significant effect on the investigated trait $(P<0.05)$, post-hoc analysis was performed (description of differences between groups). Fisher's LSD (least square difference) test was used for calculation of differences between groups at $P<0.05$ level. Presented values were expressed as arithmetic mean $(\bar{x})$ and standard deviation (SD).

\section{Results}

In comparison with group P1 $(0.512 \mathrm{mg} / \mathrm{kg}$ dry matter $)$, significantly
cle tissue was determined in group $\mathrm{P} 2$

Organic selenium at the amount $0.5 \mathrm{mg} / \mathrm{kg}$ was 
Table 2 summarizes the content of fatty acids in lipids of thigh muscle tissue, stated as $\%$ of total fatty acids. According to the profile of fatty acids in lipids of thigh muscles of two broiler groups, portions of lauric, myristic, pentadecanoic, heptadecanoic, arachidonic, behenic and lignoceric fatty acids did not significantly differ. Group P2 exhibited significantly higher portion of stearic acid (6.201\%) than Group P1 (5.898\%). Portion of total saturated fatty acids (SFA) was similar in both groups, being $27.92 \%$ in P1 and $27.21 \%$ in $\mathrm{P} 2$. Comparing $\mathrm{P} 2$ and $\mathrm{P} 1$ groups, significantly $(P<0.05)$ smaller portion of dihomo- $\gamma$-linolenic $(0.254 \%$ and $0.348 \%$, respectively) and arachidonic $(0.665 \%$ and $0.753 \%$, respectively) fatty acids, as well as total monounsaturated fatty acids $(36.74 \%$ and

Table 2. Content of fatty acids in lipids of thigh muscle tissue in two groups of broilers

\begin{tabular}{lcc}
\hline Fatty acids (\%) & Group P1 & Group P2 \\
\hline Lauric (C12:0) & $0.019 \pm 0.000$ & $0.019 \pm 0.000$ \\
Myristic (C14:0) & $0.392 \pm 0.026$ & $0.389 \pm 0.024$ \\
Pentadecanoic (C15:0) & $0.059 \pm 0.008$ & $0.062 \pm 0.004$ \\
Palmitic (C16:0) & $21.24 \pm 1.126$ & $20.25 \pm 1.516$ \\
Heptadecanoic (C17:0) & $0.106 \pm 0.012$ & $0.103 \pm 0.004$ \\
Stearic (C18:0) & $5.898 \pm 0.315^{\mathrm{b}}$ & $6.201 \pm 0.103^{\mathrm{a}}$ \\
Arachidic (C20:0) & $0.107 \pm 0.021$ & $0.097 \pm 0.017$ \\
Behenic (C22:0) & $0.053 \pm 0.004$ & $0.050 \pm 0.008$ \\
Lignoceric (C24:0) & $0.037 \pm 0.017$ & $0.030 \pm 0.000$ \\
\hline$\sum$ SFA & $27.92 \pm 1.29$ & $27.21 \pm 1.41$ \\
\hline Myristoleic (C14:1) & $0.108 \pm 0.013$ & $0.098 \pm 0.016$ \\
Palmitoleic (C16:1) & $4.854 \pm 0.457$ & $4.146 \pm 1.027$ \\
Oleic (C18:1n9) & $34.261 \pm 1.160^{\mathrm{a}}$ & $32.081 \pm 1.636^{\mathrm{b}}$ \\
Eicosenoic (C20:1) & $0.271 \pm 0.008$ & $0.281 \pm 0.016$ \\
Nervonic (C24:1) & $0.107 \pm 0.023^{\mathrm{b}}$ & $0.138 \pm 0.012^{\mathrm{a}}$ \\
\hline$\sum$ MUFA & $39.60 \pm 1.24^{\mathrm{a}}$ & $36.74 \pm 2.58^{\mathrm{b}}$ \\
\hline Linoleic (C18:2n-6) & $24.878 \pm 2.129$ & $27.533 \pm 3.152$ \\
$\gamma$-linolenic (C18:3n-6) & $0.139 \pm 0.008^{\mathrm{b}}$ & $0.159 \pm 0.014^{\mathrm{a}}$ \\
Eicosadienoic (C20:2n6) & $0.207 \pm 0.018^{\mathrm{b}}$ & $0.267 \pm 0.045^{\mathrm{a}}$ \\
Dihomo- $\gamma$-linolenic (C20:3n-6) & $0.348 \pm 0.038^{\mathrm{a}}$ & $0.254 \pm 0.026^{\mathrm{b}}$ \\
Arachidonic (C20:4n-6) & $0.753 \pm 0.021^{\mathrm{a}}$ & $0.665 \pm 0.077^{\mathrm{b}}$ \\
\hline$\sum \mathrm{n}-6$ PUFA & $26.33 \pm 2.08$ & $28.88 \pm 3.24$ \\
\hline$\alpha$-linolenic (C18:3n-3) & $4.755 \pm 0.603^{\mathrm{b}}$ & $5.692 \pm 0.624^{\mathrm{a}}$ \\
Eicosatrienoic (C20:3n-3) & $0.063 \pm 0.004$ & $0.074 \pm 0.012$ \\
EPA (C20:5n-3) & $0.107 \pm 0.009$ & $0.100 \pm 0.008$ \\
DPA (C22:5n-3) & $0.245 \pm 0.012$ & $0.258 \pm 0.017$ \\
DHA (C22:6n-3) & $0.107 \pm 0.004$ & $0.127 \pm 0.025$ \\
\hline$\sum \mathrm{n}-3$ PUFA & $5.27 \pm 0.58^{\mathrm{b}}$ & $0.064^{\mathrm{a}}$ \\
\hline n6/n3 PUFA & $5.01 \pm 0.18^{\mathrm{a}}$ & 0.112 \\
Other fatty acids & $0.871 \pm 0.197$ & \\
\hline & & \\
\hline & & \\
\hline
\end{tabular}

Data are expressed as $\bar{x} \pm \mathrm{SD}, \bar{x}$ - arithmetic mean, SD - standard deviation, SFA - saturated fatty acids, MUFA - monounsaturated fatty acids, PUFA - polyunsaturated fatty acids, a,b - statistical difference $(P<0.05)$. Group P1 - broiler fed with no selenium supplement, group P2 - broilers fed diet supplemented with $0.5 \mathrm{mg} \mathrm{Se} / \mathrm{kg}$ of feed ( $n=7$ samples per group). 
$39.60 \%$, respectively) were found. Portion of linoleic fatty acid was higher in P2, however, the difference relating to P1 was not significant $27.533 \%$ and $24.878 \%$, respectively; $P>0.05)$. According to the profile of fatty acids, broilers from P2 compared to P1 had higher portion of $\gamma$-linolenic $(0.159 \%$ and $0.139 \%$, respectively) and eicosadienoic $(0.267 \%$ and $0.207 \%$, respectively) fatty acids.

Group P2 had higher portion of total n-6 PUFA (28.88\%) than P1 (26.33\%), however, the difference was not significant. The same trend was noticed in total n-3 PUFA, with exception of significantly higher value of n-3 PUFA in lipids of thigh muscle tissue of P2 group than of P1 (6.25\% and 5.27\%, respectively). Furthermore, P2 had significantly higher portion of $\alpha$-linolenic acid ( $\alpha \mathrm{LNA})$ than P1 (5.692\% and $4.755 \%$, respectively). The investigated groups did not exhibit a significant difference in portions of other $n-3$ fatty acids, however, it should be pointed out that portions of docosapentaenoic (DPA) and docosahexaenoic acid (DHA) were higher in P2 with diets supplemented with $0.5 \mathrm{mg}$ selenium $/ \mathrm{kg}$ of feed. The ratio of stated fatty acids was in accordance with total $\mathrm{n}-6$ PUFA and n-3 PUFA. It was determined that selenium contained in feed had a significant effect $(P<0.05)$ on the $n 6 / \mathrm{n} 3$ PUFA ratio. Smaller ratio of $\mathrm{n} 6 / \mathrm{n} 3$ PUFA was determined in the P2 (4.62:1), while the ratio in P1 was 5.01:1. The obtained results proved that selenium contained in feed at the amount of $0.5 \mathrm{mg} / \mathrm{kg}$ affected portions of total fatty acids in lipids of thigh muscle tissue, i.e. influenced the increase of total n-3 PUFA portion, and decreased portions of total SFA and MUFA.

Table 3 shows that the increase of selenium content in broiler feed did not have effects on the intensity of lipid oxidation in thigh muscle tissue $(P>0.05)$.

Table 3. Values of thiobarbituric acid reactive substances in thigh muscles of broilers

\begin{tabular}{lcc}
\hline \multirow{2}{*}{ Experimental group } & \multicolumn{2}{c}{ TBARS (nmol MDA/g of tissue) } \\
\cline { 2 - 3 } & $\begin{array}{c}\text { Fresh muscle tissue } \\
(\mathrm{n}=8 \text { samples per group) }\end{array}$ & $\begin{array}{c}\text { Muscle tissue kept at }-20{ }^{\circ} \mathrm{C} \text { for } 28 \\
\text { days }(\mathrm{n}=6 \text { samples per group) }\end{array}$ \\
\hline P1 & $5.82 \pm 2.21$ & $6.93 \pm 1.45$ \\
P2 & $5.50 \pm 1.94$ & $6.46 \pm 1.87$ \\
\hline$P$-value & $P=0.765$ & $P=0.638$ \\
\hline
\end{tabular}

Data are expressed as $\bar{x} \pm \mathrm{SD}, \bar{x}$ - arithmetic mean, SD - standard deviation, TBARS - thiobarbituric acid reactive substances, MDA - malonaldehyde. Group P1 - broiler fed with no selenium supplement, group P2 - broilers fed diet supplemented with $0.5 \mathrm{mg} \mathrm{Se} / \mathrm{kg}$ of feed.

Values of thiobarbituric acid reactive substances (TBARS) of fresh meat of P1 and P2 groups were $5.50 \mathrm{nmol} \mathrm{MDA} / \mathrm{g}$ of thigh muscle tissue and $5.82 \mathrm{nmol} \mathrm{MDA} / \mathrm{g}$ of thigh muscle tissue, respectively, whereas these values in meat kept at $-20{ }^{\circ} \mathrm{C}$ for 28 days were $6.93 \mathrm{nmol} \mathrm{MDA} / \mathrm{g}$ of tissue and $6.46 \mathrm{nmol} \mathrm{MDA} / \mathrm{g}$ of tissue, respectively.

\section{Discussion}

Ševčíková et al. (2006) stated that increased content of selenium in broiler diets significantly increased its content in thigh muscle tissue, which is in accordance with our results. Kralik et al. (2012) reported that increased amount of selenium in broiler feed affected its better deposition in muscle tissue of breasts. They also determined that selenium had a significant effect on the change of fatty acid profile in lipids of breast muscles, within which increased content of selenium in feed affected the increase of $\alpha$-linolenic acid ( $\alpha \mathrm{LNA}$ ), eicosapentaenoic acid (EPA), docosapentaenoic acid (DPA) and 
docosahexaenoic acid (DHA), as well as portion of total n-3 PUFA. Similar results were also pointed out by Haug et al. (2007), who determined that selenium supplemented to broiler feed had a significant effect on the content of basic n-3 PUFA (EPA, DPA and DHA) in thigh muscle tissue. The authors determined that the increase of organic selenium contained in feed influenced the increase of stated fatty acids contained in thigh muscle tissue $(P<0.05)$. That fact can be explained with the higher concentration of selenium in feed which affected activities of $\Delta^{6}-, \Delta^{5}$ - and $\Delta^{4}$-desaturase and elongase that catalyze elongation and desaturation of short-chain fatty acids into long-chain fatty acids, or that intake causes deceleration in degradation of long-chain fatty acids in oxidation processes. Betti et al. (2009) observed that more $\alpha$-LNA was accumulated in lipids of thigh muscle tissues than of breast muscle tissue, and it is known that unsaturated fatty acids, among them also $\alpha$-LNA, are more susceptible to oxidation and creation of peroxides and aldehydes. These compounds, formed during lipid oxidation, are responsible for reducing the quality of PUFA enriched animal products during storage time (Leskanich and Noble 1997). If broiler feed is supplemented only with sunflower oil, portion of $\alpha$ LNA is lower than in case of linseed oil supplementation. Krejčí-Treu et al. (2010) reported that feeding broilers with diets enriched with sunflower oil resulted in the content of $\alpha$ LNA in lipids being $1.04 \mathrm{~g} / 100 \mathrm{~g}$ of lipids, whereas in the case of dietary supplementation with linseed oil that content was significantly higher, being $7.47 \mathrm{~g} / 100 \mathrm{~g}$ of lipids in thigh muscle. Yaroshenko et al. (2004) determined significantly lower concentration of MDA in breasts and thigh muscles in an experimental group of broilers that were fed diets supplemented with selenium $(0.4-0.8 \mathrm{mg} / \mathrm{kg})$ compared to control broilers that consumed standard diet.

We found in our study that except for sunflower oil, feeding treatments were composed of linseed oil that is rich in $\alpha$ LNA, which caused enrichment with n-3 PUFA in lipids of thigh muscle tissue. Dietary supplementation of selenium at the amount of $0.5 \mathrm{mg} / \mathrm{kg}$ affected lowering of lipid oxidation in muscle tissue of fresh thighs as well as in muscle tissue of thighs kept at $-20{ }^{\circ} \mathrm{C}$ for 28 days. Use of linseed oil in broiler diets and supplementation of organic selenium at the amount of $0.5 \mathrm{mg} / \mathrm{kg}$ of feed can enrich thigh meat with selenium (from $0.511 \mathrm{mg} / \mathrm{kg}$ to $1.071 \mathrm{mg} / \mathrm{kg}$ dry matter), as well as increase portion of total $\mathrm{n}-3$ PUFA from 5.27 to $6.25 \%$. Supplementation of linseed oil and organic selenium to broiler diets was efficient because it affected the increase in portion of total n-3 PUFA by $18.6 \%$, as well as the increase of selenium by $191.8 \%$ in thigh muscle tissue. Since selenium and n-3 PUFA are nutricines, produced broiler meat may be considered as functional food.

\section{Acknowledgment}

The research was carried out within the project "Specificities of pig and poultry growth and quality of products" (No. 079-0790566-0567), funded by the Ministry of Science, Education and Sports of the Republic of Croatia.

\section{References}

Betti M, Schneider BL, Wismer WV, Carney VL, Zuidhof MJ, Renema RA 2009: Omega-3-enriched broiler meat: 2. Functional properties, oxidative stability, and consumer acceptance. Poult Sci 88: 1085-1095

Csapó J, Sugár L, Horn A, Csapó Jne 1986: Chemical composition of milk from red deer, roe and fallow deer kept in captivity. Acta Agron Hun 3-4: 359-372

Davidowski L 1993: Perkin Elmer ICP Application Study Number 67

Haug A, Eich-Greatorex S, Bernhoft A, Wold JP, Hetland H, Christophersen OA, Sogn T 2007: Effect of dietary selenium and omega-3 fatty acids on muscle composition and quality in broilers. Lipids Health Dis 6: 29-38

Kralik Z, Kralik G, Grčević M, Suchý P, Straková E 2012: Effects of increased content of organic selenium in feed on the selenium content and fatty acid profile in broiler breast muscle. Acta Vet Brno 81: 31-35

Krejčí-Treu T, Straková E, Suchý P, Herzig I 2010: Effect of vegetable oil fortified feeds on the content of fatty acids in breast and thigh muscles in broiler chickens. Acta Vet Brno 79: 21-28

Leskanich CO, Noble RC 1997: Manipulation of the $\omega-3$ polyunsaturated fatty acid composition of avian eggs and meat. World Poult Sci J 53: 155-183

López-Ferrer S, Baucells MD, Barroeta AC, Blanch A, Grashorn MA 1999: N-3 enrichment of chicken meat using fish oil: Alternative substitution with rapeseed and linseed oils. Poult Sci 78: 356-365 
López-Ferrer S, Baucells MD, Barroeta AC, Grashorn, MA 2001: N-3 enrichment of chicken meat. 1. Use of very long-chain fatty acids in chicken diets and their influence on meat quality: Fish oil. Poult Sci 80: 741-752

Miret S, Sáiz MP, Mitjavilo MT 2003: Effects of fish oil- and olive oil-rich diets on iron metabolism and oxidative stress in the rat. Brit J Nutr 89: 11-18

Ohkawa H, Ohishi N, Yagi K 1979: Assay for lipid peroxides in animal tissues by thiobarbituric acid reaction. Anal Biochem 95: 351-358

Sparks NHC 2006: The hen's egg-is its role in human nutrition changing? Worlds Poult Sci 62: 308-315

Ševčíková S, Skřivan M, Dlouhá G, Koucký M 2006: The effect of selenium source on the performance and meat quality of broiler chickens. Czech J Anim Sci 51: 449-457

Yaroshenko FO, Surai PF, Yaroshenko YF, Karadas F, Sparks NHC 2004: Theoretical background and commercial application of production of Se-enriched chicken. In: Proceedings of XXII World's Poultry Congress, Worlds' Poultry Association (WPSA), Istanbul, Turkey 